\title{
Avaliação da mortalidade por COVID-19 no Nordeste do Brasil
}

\section{Evaluation of COVID-19 mortality in Northeastern Brazil}

Recebimento dos originais: 01/05/2021

Aceitação para publicação: 31/06/2021

\section{Diogo Leonardo Santos Silva}

Instituição: Universidade Federal de Campina Grande (UFCG), Cuité - Paraíba.

\section{Alison Pontes da Silva}

Instituição: Universidade Federal de Campina Grande (UFCG), Cuité - Paraíba.

\section{Letícia de Oliveira Silva}

Instituição: Universidade Federal de Campina Grande (UFCG), Cuité - Paraíba.

André Alan Santos Silva

Instituição: Universidade Federal de Campina Grande (UFCG), Cuité - Paraíba.

\section{Glaucia Veríssimo Faheina Martins}

Instituição: Universidade Federal de Campina Grande (UFCG), Cuité - Paraíba.

\section{RESUMO}

A doença do coronavírus 2019 afetou todos os estados da região Nordeste no tocante à mortalidade, com destaque para os estados de Sergipe, Ceará e Pernambuco que detiveram as maiores taxas brutas de mortalidade.

Palavras-chave: COVID-19, Pandemia; SARS-CoV-2.

\section{ABSTRACT}

Coronavirus 2019 disease affected all states in the Northeast region in terms of mortality, with the states of Sergipe, Ceará and Pernambuco having the highest crude mortality rates.

Keywords: COVID-19, Pandemic; SARS-CoV-2.

\section{INTRODUÇÃO}

A COVID-19, como é conhecida a doença do coronavírus 2019 (DA SILVEIRA MOREIRA R, 2020), trata-se de uma infecção viral que acomete o sistema respiratório. Além disso, o agente etiológico desta doença é o coronavírus da síndrome respiratória aguda grave 2 (SARS-CoV-2) (LOGUNOV DY, et al., 2020). Em relação à gravidade dos casos, os acometidos pelo novo coronavírus podem desenvolver distúrbios fisiológicos leves ou até mesmo casos graves, resultando em morte (DE OLIVEIRA ABUD C e DE SOUZA LP, 2020; HALLAL PC, et al., 2020).

O vírus causador da COVID-19 é altamente transmissível (DE OLIVEIRA ABUD C e DE SOUZA LP, 2020), bem como possui rápida disseminação (DE OLIVEIRA ABUD C e DE SOUZA LP, 2020; 
HALLAL PC, et al., 2020). Estes fatores fizeram com que a Organização Mundial da Saúde categorizasse a COVID-19 como uma pandemia (HALLAL PC, et al., 2020).

Referente à região Nordeste do Brasil, o contexto crônico de vulnerabilidade social enfrentada por esta região contribui para a presença de altas taxas de mortalidade calculadas para esta região do país (FREIRE DE SOUZA CD, et al., 2020). Sendo assim, julga-se necessário verificar a mortalidade por COVID-19 nesta região.

\section{OBJETIVO}

Avaliar as taxas brutas de mortalidade (TBM) causadas pela COVID-19 nos estados que compõem a região Nordeste do Brasil durante o período temporal de 27 de março a 15 de fevereiro de 2021.

\section{MÉTODO}

Trata-se de um estudo documental, retrospectivo, com abordagem quantitativa, realizado a partir de dados epidemiológicos fornecidos pela plataforma Coronavírus Brasil (BRASIL, 2020). Estes dados referem-se ao número de habitantes, óbitos acumulados e a mortalidade (a cada 100.000 habitantes) por COVID-19 na região Nordeste do Brasil, de 27 de março de 2020 a 15 de fevereiro de 2021.

A coleta dos dados ocorreu no dia 15 de fevereiro de 2021, às 20:00 horas. Posteriormente, os dados coletados foram expostos em uma tabela construída a partir do Microsoft Excel 2010. A TBM a cada 100.000 habitantes pode ser calculada pela seguinte fórmula: $\mathrm{TBM}=$ (Número de óbitos / Número de habitantes do local) x 100.000 (BAZO PAZ AP et al., 2016).

\section{RESULTADOS}

Os dados referentes ao número de habitantes, número de óbitos, bem como a mortalidade a cada 100.000 habitantes causada pela COVID-19 nos estados da região Nordeste do Brasil, no período de 27 de março de 2020 a 15 de fevereiro de 2021, encontram-se organizados abaixo (tabela 1).

Tabela 1. Mortalidade por COVID-19 na região Nordeste do Brasil, durante período temporal de 27 de março de 2020 a 15 de fevereiro de 2021.

\begin{tabular}{cccc}
\hline Estado & $\mathbf{N}^{\circ}$ de habitantes & $\mathbf{N}^{\circ}$ de óbitos & $\begin{array}{c}\text { Taxa de } \\
\text { mortalidade }\end{array}$ \\
\hline Rio Grande do Norte & 3.506 .853 & 3.413 & 97 \\
Paraíba & 4.018 .127 & 4.255 & 106 \\
Ceará & 9.132 .078 & 10.836 & 119 \\
Piauí & 3.273 .227 & 3.190 & 97 \\
Bahia & 14.873 .064 & 10.798 & 73 \\
Maranhão & 7.075 .181 & 4.860 & 69 \\
Sergipe & 2.298 .696 & 2.881 & 125
\end{tabular}




\begin{tabular}{cccc} 
Alagoas & 3.337 .357 & 2.873 & 86 \\
Pernambuco & 9.557 .071 & 10.677 & 112 \\
\hline & Fonte: Dados extraídos de BRASIL, 2021.
\end{tabular}

estado com o maior número de habitantes foi a Bahia (14.873.064), seguido por Pernambuco (9.557.071), Ceará (9.132.078), Maranhão (7.075.181), Paraíba (4.018.127), Rio Grande do Norte (3.506.853), Alagoas (3.337.357), Piauí (3.273.227) e Sergipe (2.298.696).

O estado com o maior número de óbitos foi o Ceará (10.836), seguido por Bahia (10.798), Pernambuco (10.677), Maranhão (4.860), Paraíba (4.255), Rio Grande do Norte (3.413), Piauí (3.190), Sergipe (2.881) e Alagoas (2.873).

Diante dos dados apresentados é evidente que, o estado de Sergipe apresentou a maior taxa de mortalidade a cada 100.000 habitantes (125), seguido pelos estados do Ceará (119), Pernambuco (112), Paraíba (106), Rio Grande do Norte (97) e Piauí (97), bem como Alagoas (86), Bahia (73) e Maranhão (69).

\section{DISCUSSÃO}

Diversos fatores podem influenciar na variação da taxa de mortalidade entre os estados do Nordeste. Prevalência de comorbidades, quantitativo de testes realizados, deslocamento de pessoas em aeroportos e medidas de distanciamento social são apenas alguns exemplos. Um estudo com dados do Nordeste até 21 de julho de 2020 mostrou que o estado de Sergipe tinha a menor razão entre o número de testes realizados e o número de casos positivos, indicando que a testagem era voltada especialmente para casos de maior gravidade. A presença de aeroportos internacionais também pode exercer um papel na disseminação do vírus, algo que pode estar associado à alta mortalidade no Ceará (KERR L, et al., 2020).

\section{CONSIDERAÇÕES FINAIS}

Em síntese, é perceptível que diversos fatores podem influenciar a mortalidade por COVID-19. Sendo assim, minimizar estes fatores pode ser considerado uma estratégia que pode contribuir para a redução do número de óbitos na região Nordeste do Brasil.

Para tal, são necessárias medidas públicas direcionadas à minimização da transmissão, bem como a redução dos fatores que podem contribuir para o aumento da mortalidade por COVID-19 na região Nordeste do Brasil. 


\section{REFERÊNCIAS}

1. BAZO PAZ AP, et al. MORTALITY FROM CERVICAL CANCER IN SANTA CATARINA, BRAZIL, 2000-2010. Revista de Pesquisa: Cuidado é Fundamental Online, v. 5, n. 2, p. 3780-3787, 2013.

2. BRASIL. COVID-19 no Brasil. 2021. Disponível em: https://susanalitico.saude.gov.br/extensions/covid-19_html/covid-19_html.html. . Acessado em: 15 de março de 2021.

3. DA SILVEIRA MOREIRA R. COVID-19: unidades de terapia intensiva, ventiladores mecânicos e perfis latentes de mortalidade associados à letalidade no Brasil. Cadernos de Saúde Pública, v. 36, v. 5, p. e00080020, 2020.

4. DE OLIVEIRA ABUD C, DE SOUZA LP. Uso obrigatório de máscara facial para conter a COVID19 no Brasil: limitação legítima ao direito fundamental de autodeterminação. Vigilância Sanitária em Debate: Sociedade, Ciência \& Tecnologia (Health Surveillance under Debate: Society, Science \& Technology)-Visa em Debate, v. 8, n. 3, p. 34-43, 2020.

5. FREIRE DE SOUZA CD, et al. Evolução espaçotemporal da letalidade por COVID-19 no Brasil, 2020. Jornal Brasileiro de Pneumologia, v. 46, n. 4, 2020.

6. HALLAL PC, et al. Evolução da prevalência de infecção por COVID-19 no Rio Grande do Sul, Brasil: inquéritos sorológicos seriados. Ciência \& Saúde Coletiva, v. 25, supl. 1, p. 2395-2401, 2020.

7. KERR L, et al. COVID-19 no Nordeste brasileiro: sucessos e limitações nas respostas dos governos dos estados. Ciência \& Saúde Coletiva, v. 25, supl. 2, p. 4099-4120, 2020.

8. LOGUNOV DY, et al. Safety and immunogenicity of an rAd26 and rAd5 vector-based heterologous prime-boost COVID-19 vaccine in two formulations: two open, non-randomised phase 1/2 studies from Russia. The Lancet, v. 396, n. 10255, p. 887-897, 2020. 